\title{
The study on experts' evaluation index system of city appearance and environmental sanitation
}

\author{
Xuwen Gao, Chao Xu, Jiancheng Chen \\ Beijing Forestry University, Beijing, China \\ 824201982@qq.com,xuchao@bjfu.edu.cn, chenjc1963@163.com
}

\begin{abstract}
Recently, the quality of the work of the city appearance and environmental sanitation has been constantly improved, however, the assessment of the work has not been standardized and institutionalized and the existing professional assessment and social evaluation are certain one-sided. In that case, it is an inexorable trend to construct the multiple evaluation index system of the city appearance and environmental sanitation. This paper studies the expert evaluation index of the city appearance and environmental sanitation using Delphi method, questionnaire survey, AHP and many other methods. Moreover, it sets up an expert evaluation system of city appearance and environmental sanitation, which has good practicability and maneuverability and can reflect the development trend of the city appearance and environmental sanitation.

Index Terms - city appearance and environmental sanitation, index system, Delphi method
\end{abstract}

\section{Introduction}

The city appearance and environmental sanitation is the outer form of the city, which reflects the city's external image and spiritual connotation and involves broad extent. It contains many jobs such as the planning and construction of the urban roads, the maintenance and cleaning of the urban roads and recycling and disposal of domestic waste and so on. Nearly every city has its own professional evaluation system to assess the work of the city appearance and environmental sanitation as well as the social satisfaction evaluation system for public, but the results of the two systems differ greatly and all of them are certain one-sided. Therefore, they may play negative role in the public sanitation department which is continuing improving. In that case, we should establish a professional evaluation index system to form the expert evaluation model in order to reveal the practical situation of the city appearance and environmental sanitation more scientifically, objectively and fairly.Delphi method is a qualitative forecasting method that is common used in social science research. It gets the final prediction, decision or index system that are approved by the majority of the experts mainly through several rounds of experts questionnaires and certain statistic methods. It is representative and reliable.

\section{II . The Establishment Of Evaluation Index System}

A . Research steps

The original selection of the index: This paper consults relative literature, national and local policies and regulations as well as evaluation index on the city appearance and environmental sanitation. It also refers to some statistical yearbook. All of this lays a good foundation for us to select index.

We consider that this index system should include spiritual and material aspects. Meanwhile, the whole evaluation system is conducted by the combination of qualitative and quantitative. To some index that can be measured, we identify it as quantitative index. As to other index that can be observed but can hardly be measured, we usually call them qualitative index.

Experts selection: How to select experts is the key problem affecting the success of Delphi method. This study selects experts mainly based on experts' knowledge structure, their major, their working nature and working years(represent as the professional technical post). As this study relates to many subjects such as environmental management, environmental sanitation and city construction and so on, the experts we select not only come from colleges and universities but also from scientific research institutions. We also invite many managers and experts that have rich practical experience.

Experts consultation: Our study invites a group of experts and academic advisers coming from the relevant department of government, colleges and universities and scientific research institution. Firstly, we introduce some background information and the first draft of evaluation index. Then we conduct a field survey according to the evaluation index. Finally, we organized an information discussion, where experts can put forward the problems they notice via field survey as well as the index which they consider as important but is not included in the first draft, and thus provide the initial determination of index system with necessary supplement.

Questionnaire survey: After adopting the suggestion from the expert, we adjust the index and make a questionnaire survey towards experts examined indexes which are related to city appearance and the quality of work on environmental sanitation. In this way, we are eager to understand ideas from the public, and design experts evaluation index system which is able to reflect the practical situation about the city appearance and environmental sanitation more objectively.

Form the rudiment of the index system: We firstly analyze the results of the questionnaire survey, and then absorb opinions and suggestions. Finally we modify part of the original index. In this way, we set up the second grade index and consequently determine the initial index system. 
Expert judgment: Using Delphi method, this study asks the experts to give score on the importance of all the index of the system. Moreover, it evaluate independently according to the familiarity of the evaluation index and the basis for scoring on every index. Finally, it determine the experts evaluation index system of city appearance and environmental sanitation.

\section{$B$. Research method and results evaluation}

Sampling survey: The questionnaire survey is carried out using the method of street intercept survey. Firstly, the study selects an region where the people volume of flow is more masses, and then according to a certain proportion it conducts a sample survey aiming at people who differ in age, income, occupation and residence, which efficiently reduces the insufficiency resulting from the poor randomness of street intercept survey.

The key factors affecting the sample size are characteristics of investigation object, investigation precision, allowed error and funds. Based on the principle of simple random sampling, considering related factors, the sampling error must be less than $5 \%$ while the confidence level was $95 \%$.

$$
\text { The sample size: } \mathrm{n}=\frac{\mathrm{p}(1-\mathrm{p}) * \mathrm{Z}^{2}}{\mathrm{D}^{2}}
$$

P: the expectation of the proportion of the target population. Use the most conservative method of estimation, in this way, $\mathrm{P}=50 \%$.

$\mathrm{D}$ : absolute error. This survey requires that the error is less than $5 \%$, that is $\mathrm{D}=5 \%$.

$\mathrm{Z}: \mathrm{Z}$ statistic at the confidence level. The confidence level in the survey was $95 \%$, which means that the reliable degree that of which the parameters of the population are in the given confidence interval is $95 \%$, so $\mathrm{Z}$ statistic is 1.96 .

$$
\mathrm{N}=\frac{0.5 *(1-0.5) * 1.96^{2}}{0.05^{2}}=384
$$

Based on past experience, we considered the effective return-ratio to be $90 \%$. N0 $=384 / 0.9=427$

754 questionnaires are collected out of 755 with the return-ratio almost $100 \%$. The number of valid samples that are used to analyze is 688 , so the effective return-ratio is $91.2 \%$.

Active coefficient of experts: The active coefficient of experts is represented as the recovery rate of the expert consulting tables, which indicates the concern extent of the experts of the survey.

This study totally sent out 25 questionnaires and collected 25. Consequently, the active coefficient of experts is $100 \%$. There are 23 experts gave their suggestions to the index system, which accounts for $92 \%$ of the total number of the experts. This indicates that experts showed a high interest in our study and really want to cooperate with us.

The authority degree of experts: The authority degree of experts is determined by two factors, one is the basis for the judgment that experts make, which is presented as $\mathrm{Ca}$; the other is the familiarity of the experts towards the problem expresses by Cs. The authority coefficient $(\mathrm{Cr})$ is the arithmetical mean of $\mathrm{Ca}$ and $\mathrm{Cs}$.

According to the experts evaluation towards the first grade index in the questionnaire, we do the calculation. The result shows that when the coefficient $\mathrm{Ca}$ is 0.635 the index is first grade. The total familiarity of the experts towards the first grade index is the mean of the familiarity towards each index (see Table 1).

The authority coefficient $(\mathrm{Cr})$ towards the first grade index that is the arithmetic mean of $\mathrm{Ca}$ and $\mathrm{Cs}$ is 0.715 . In the same way, the authority coefficient $(\mathrm{Cr})$ towards the second grade index is 0.707 (see Table 2).

It is generally believed that $\mathrm{Cr} \geq 0.70$ is accepted.

TABLE I The Experts Familiarity Degree Towards The First Grade Index

\begin{tabular}{|l|c|}
\hline The first grade index & Familiarity degree \\
\hline Planning and infrastructure & 0.775 \\
\hline Environmental quality and management & 0.857 \\
\hline City appearance & 0.8 \\
\hline Sanitary condition & 0.886 \\
\hline characteristic projects & 0.657 \\
\hline Total familiarity degree & 0.795 \\
\hline
\end{tabular}

TABLE II The authority degree of experts towards index

\begin{tabular}{|c|c|c|c|}
\hline & $\begin{array}{c}\text { Judgment } \\
\text { basis Ca }\end{array}$ & $\begin{array}{c}\text { Familiarity } \\
\text { degree Cs }\end{array}$ & $\begin{array}{c}\text { Authority } \\
\text { degree Cr }\end{array}$ \\
\hline The first grade index & 0.635 & 0.795 & 0.715 \\
\hline The second grade index & 0.639 & 0.774 & 0.707 \\
\hline
\end{tabular}

The concentration degree and coordination degree of the suggestions of experts: The concentration degree of the opinions of experts reflects that whether they are agree on the issue including arithmetic mean of their scores and the frequency of the full mark. Larger arithmetic mean means the index is more important. The frequency of the full mark can be the supplementary index to the arithmetic mean and it also indicates that the importance of the index is higher with the larger frequency. The coordination degree of the suggestions of experts is used to judge whether they have serious disagreement on evaluation of each index. It mainly consists of the coefficient of variation and the coordination index of experts' suggestions W.

Coefficient of variation indicates fluctuation degree or coordination degree of relative importance of certain index. The smaller the coefficients of variation are, the higher the concentration of experts' suggestions is. In this way, the coordination degree of the experts' suggestions is higher. When the coefficient of variation is equal to or greater than 0.25 , it is generally believed that experts have serious disagreement on the index. 
The coordination index of experts' suggestions W reflects the coordination degree towards the experts' suggestions of different index. It ranged between 0 and 1. When $\mathrm{W}$ is larger, the coordination degree is better.

According to the arithmetic mean and full score frequency of the opinion feedback of the first grade index(see in Table 3), the arithmetic mean of all index except the characteristic projects is higher than 8.5 , which indicates the importance of all the index. The highest frequency of full score is environmental quality and management (higher than $70 \%$ ), the second one is planning and infrastructure(higher than $60 \%$ ), the third are city appearance and sanitary condition, and towards these indexes less than half of the experts gave full score. There are five coefficients of variation of the first grade index lying between 0.112-0.230, which indicates that experts' opinions are rather concentrated.

TABLE III The concentration degree and coordination degree of the suggestions of experts

\begin{tabular}{|c|c|c|c|}
\hline The first grade index & $\begin{array}{c}\text { Arithmeti } \\
\text { c mean }\end{array}$ & $\begin{array}{c}\text { full score } \\
\text { frequency }\end{array}$ & $\begin{array}{c}\text { Coefficient } \\
\text { of variation }\end{array}$ \\
\hline $\begin{array}{c}\text { Planning and } \\
\text { infrastructure }\end{array}$ & 9.250 & 0.625 & 0.112 \\
\hline $\begin{array}{c}\text { Environmental quality } \\
\text { and management }\end{array}$ & 8.857 & 0.714 & 0.220 \\
\hline City appearance & 8.571 & 0.429 & 0.176 \\
\hline Sanitary condition & 8.857 & 0.429 & 0.121 \\
\hline characteristic projects & 6.571 & 0.000 & 0.230 \\
\hline
\end{tabular}

The coefficients of variation of the second grade index lie between $0.068-0.472$, and 8 indexes' coefficients of variation are higher than 0.25 . This means that experts differ greatly in their opinions, but the arithmetic mean of all the indexes is larger than 6 . The coordination coefficient (W) of the second grade index is $0.334, \mathrm{P}<0.05$ (see in Table 4), which indicates a high coordination degree of the second grade index.

TABLE IV Experts' Opinions' Coordination Degree And X2 Text Towards The Second Grade Index

\begin{tabular}{|c|c|c|c|c|}
\hline & $\mathrm{W}$ & $\mathrm{X} 2$ & $\begin{array}{c}\text { Degree of } \\
\text { freedom }\end{array}$ & $\mathrm{P}$ \\
\hline Second grade index & 0.334 & 87.279 & 29.000 & 0.000 \\
\hline
\end{tabular}

The calculation of weight coefficient of the index: Send questionnaires to experts to get their suggestions, and then determine the weight of index of different levels using AHP. The sum of the weight of index in each level must be 1 .

\section{The construction of index system}

Based on the above method, the study sets up the experts evaluation index system, in which there are 5 first grade indexes and 30 second grade index and the black letters are 14 important indexes. Moreover, there are evaluations content or observation point under each secondary index, and we call them the third grade index. The total number of the third grade index is 79. The study then gave relevant weights to each index using AHP. Considering convenience of the application, the study simplified the weights to two decimal places. See in Table 5 .

TABLE V Experts evaluation index system of city appearance and environmental sanitation

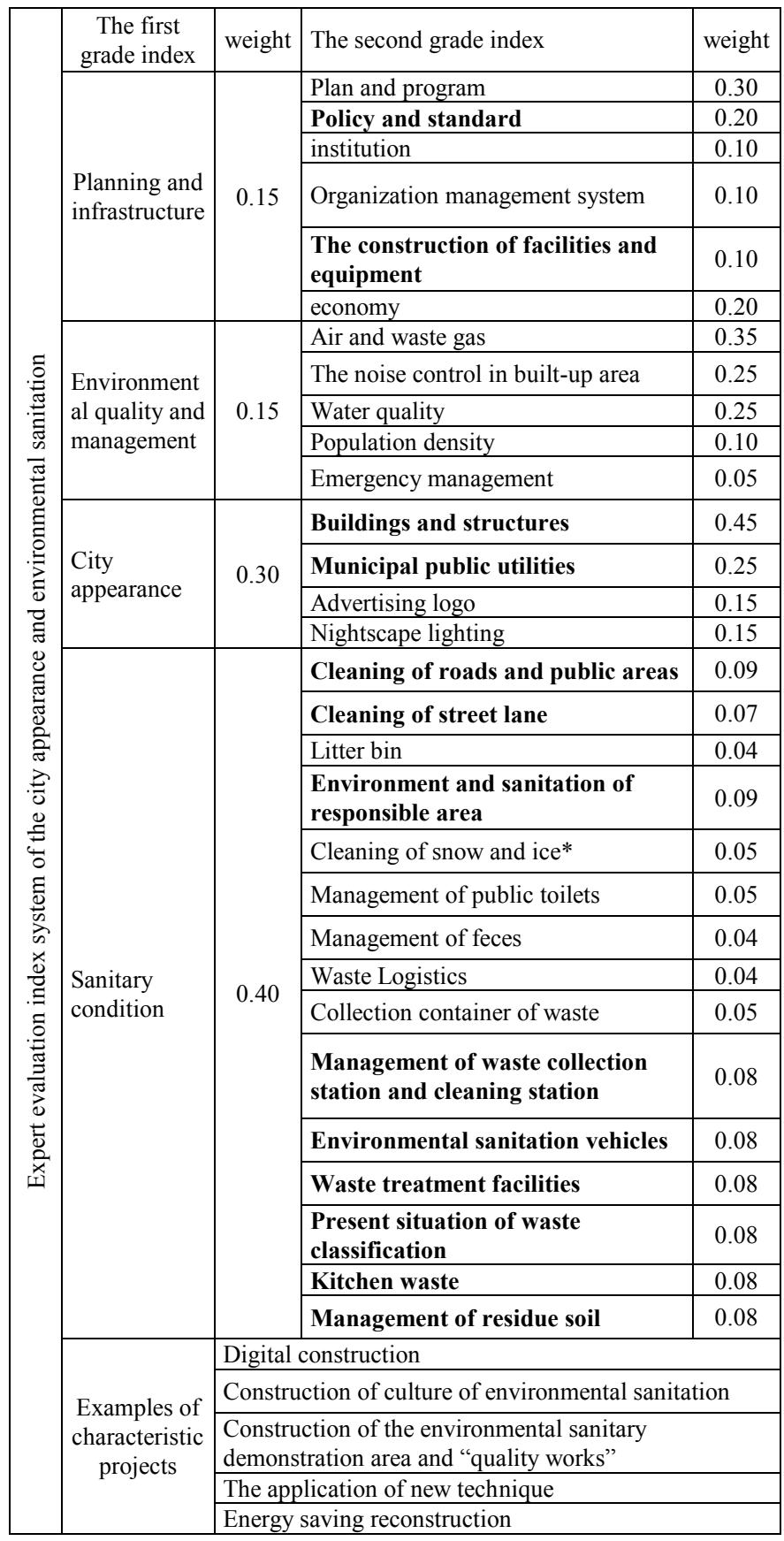

\section{Experts evaluation model}

According to the given score to each index and the weight of the index, we can calculate the comprehensive score of experts evaluation of the city appearance and environmental 
sanitation in the city or district (the total score doesn't include the fifth part: examples of characteristic projects).

$$
V_{i j}=\sum_{j=1}^{n} W_{i j} Z_{k i j}
$$

In the formula, $V_{k i}$ is the score of the secondary index given by the Kth expert; Zkij is the score given by the Kth expert of the Jth observation point which the Ith secondary index belongs to; Wij is the weight of the Jth observation point which the Ith secondary index belongs to while $n$ is the number of the observation point.

$$
\mathrm{U}_{\mathrm{ki}}=\sum_{\mathrm{i}=1}^{\mathrm{n}} \mathrm{W}_{\mathrm{i}} \mathrm{V}_{\mathrm{ki}}
$$

In the formula, Ukj is the score of the first index given by the Kth expert; $t j$ is the score of the Ith secondary index which the first index belongs to; $\lambda_{\mathrm{k}}$ is the weight of the Ith secondary index which the first index belongs to while $n$ is the number of the secondary index.

$$
\mathrm{Z}=\sum_{\mathrm{k}=1}^{\mathrm{m}} \lambda_{\mathrm{k}} \sum_{\mathrm{j}=1}^{\mathrm{n}} \mathrm{t}_{\mathrm{j}} \mathrm{U}_{\mathrm{kj}}
$$

In the formula, $\mathrm{Z}$ is the final score, $\mathrm{Ukj}$ is the score calculated by the Kth expert towards the Jth first index; t $j$ is the weight of the Jth first index; $\lambda_{\mathrm{k}}$ is the weight of the Kth expert; $n$ is the number of the first index and $m$ is the number of the experts.

The full mark is 100. Based on the score of each region, the result of the assessment can be divided into excellent, good, qualified and unqualified. The principles are as follows:

Excellent: the final score reaches 90, the score of important index reaches 85 , the region has distinctive characteristics.
Good: the final score reaches 80 , the score of important index no less than 75 , the region has characteristic projects.

Qualified: the final score reaches 70, the score of important index no less than 65.

Unqualified: the final score is less than 60.

\section{III . Discussion}

The experts' evaluation index system of city appearance and environmental sanitation is dynamic and can add or delete indexes according to the actual need of the future work. The weakness of the system is that experts evaluation differs from professional evaluation and social evaluation, it rely more on subjective scoring when having field survey, and thus it inevitably has some errors.

\section{References}

[1] heng Wen, Zhai Baohui, Zhang Xiaoxin. A Study on the Assessment of City Internalization. China Construction, 2009,(04) .

[2] Wang Weiguo, Feng Yun. A Comparative Research on Dalian's Human Living Environment with the Other 36 Domestic Cities. Ecological Economy, 2011,(05)

[3] Wang Yan, Huo Weizhou, Wang Siliang. Status Survey and Management of Environmental Sanitation in Beijing Rural Area. Environmental Sanitation Engineering, 2008,(01) .

[4] Tian Yilin, Yang Qing. Urban Disaster Response Capacity Evaluation Index System Model Design Based on AHP-DELPHI Method. Journal of Wuhan University of Technology(Transportation Science \& Engineering), 2008,(01) .

[5] He Xiuping. Discussion on System Construction of Municipal Environmental Sanitation Monitoring. Environmental Sanitation Engineering, 2007,(06) .

[6] Su Jun. Study on the Index System of Assessment in Health City Construction in Sichuan Province. Sichuan University, 2007.

[7] Ministry of Housing and Urban-Rural Development of the People's Republic of China. Announcement on Issue of The $<<$ Construction of Chinese Urban-Rural Environmental Sanitation System $>>$, [EB/OL]. http://www.mohurd.gov.cn/zcfg/jswj/csjs/200611/t20061101_157169.ht m, 2006-02-09. 